\title{
Comparative techno-economic assessment and LCA of selected integrated sugarcane-based biorefineries
}

\author{
Edgard Gnansounou*, Pavel Vaskan, Elia Ruiz Pachón \\ Bioenergy and Energy Planning Research Group, GR-GN, INTER, ENAC, Station 18, EPFL, 1015 Lausanne, Switzerland
}

\section{H I G H L I G H T S}

- The four scenarios can show a 56-70\% reduction in GHG emissions.

- Furthermore a 51-57\% reduction in Fossil depletion impact is estimated.

- The benefits of the other investigated environmental impacts are limited.

- The four scenarios are energy self-sufficient.

- Integrated sugarcane biorefineries can be economically efficient.

\section{A R T I C L E I N F O}

\section{Article history:}

Received 28 May 2015

Received in revised form 18 July 2015

Accepted 20 July 2015

Available online 26 July 2015

\section{Keywords:}

Sugarcane

Biorefinery

$1 G / 2 G$ bioethanol integration

LCA

Brazil

\begin{abstract}
A B S T R A C T
This work addresses the economic and environmental performance of integrated biorefineries based on sugarcane juice and residues. Four multiproduct scenarios were considered; two from sugar mills and the others from ethanol distilleries. They are integrated biorefineries producing first $(1 \mathrm{G})$ and second $(2 \mathrm{G})$ generation ethanol, sugar, molasses (for animal feed) and electricity in the context of Brazil. The scenarios were analysed and compared using techno-economic value-based approach and LCA methodology. The results show that the best economic configuration is provided by a scenario with largest ethanol production while the best environmental performance is presented by a scenario with full integration sugar $1 \mathrm{G} 2 \mathrm{G}$ ethanol production.
\end{abstract}

(c) 2015 Elsevier Ltd. All rights reserved.

\section{Introduction}

Over the last few years the production of second generation $(2 \mathrm{G})$ biofuels from abundant lignocellulosic biomass that can provide a sustainable energy without compromising food security has gained huge interest worldwide. According to an IEA report (IEA, 2010 ) it is concluded that $10 \%$ of global residues could yield around 155 billion litres gasoline equivalent ( $5.2 \mathrm{EJ}$ ) $2 \mathrm{G}$ ethanol or roughly $4.1 \%$ of the projected transport fuel demand in 2030 . Moreover the recent trend is furthered through the co-production of integration 1G2G ethanol, food, feeds and high-chemical valuable products (FitzPatrick et al., 2010), that promises to give significant opportunities to the development of biorefineries.

Brazil has developed extensive biofuel production capabilities (Moreira et al., 2014) which largely contribute to the country's

* Corresponding author at: Bioenergy and Energy Planning Research Group, GC A3 424 (Bâtiment GC), ENAC INTER GR-GN, EPFL, Station 18, CH-1015 Lausanne, Switzerland. Tel.: +41216930627.

E-mail address: edgard.gnansounou@epfl.ch (E. Gnansounou). energy needs and independence (Lopes Silva et al., 2014; Moreira et al., 2014). In particular, sugarcane is the main feedstock for Brazilian biofuel (Moncada et al., 2013), with 1G bioethanol from sugarcane being massively produced and commercialised in Brazil for at least forty years (Dias et al., 2013). Although 2G biofuel production has an economic potential (Gnansounou and Dauriat, 2010), its implementation is slow (Furlan et al., 2013). Several studies demonstrated the economic and environmental viability of integrated $1 \mathrm{G} 2 \mathrm{G}$ biorefineries for both ethanol production and electricity generation (Dias et al., 2010, 2013; Schaidle et al., 2011). In Brazil, this idea was furthered through the co-production of sugar, ethanol/electricity, and other co-products e.g. molasses for animal feed (Lopes Silva et al., 2014). Such integration of $1 \mathrm{G} 2 \mathrm{G}$ ethanol production with sugar mill promises to bring significant environmental and economic benefits for potential biorefinery. However whilst there were many studies on biorefineries producing $1 \mathrm{G} 2 \mathrm{G}$ ethanol and heat \& power, integration of sugar (and sugar crop derived products) with bioethanol was less investigated. In this paper methodologies were proposed for 
techno-economic assessment and Life Cycle Assessment (LCA) of integrated configurations of sugarcane-based biorefineries in the context of Brazil.

These methodologies were then applied to assess four different configurations of integrated biorefineries producing $1 \mathrm{G}$ and $2 \mathrm{G}$ ethanol, sugar, molasses (for animal feed) and electricity in the context of Brazil. The configurations included two partial integration scenarios without sugar production and two full integration scenarios. The feedstock for the different configurations included sugarcane juice, bagasse and green harvesting residues (GHRs). Each configuration was compared with a conventional multi-products reference case in order to find out the merit of the alternatives.

\section{Methods}

\subsection{Main assumptions}

The proposed methodology for techno-economic and environmental assessment of integrated sugarcane-based biorefineries includes several parts. Firstly the process simulation and scenarios definition were performed using Aspen Plus v 8.6 software. Current achievements in conversion of lignocellulose materials to ethanol were investigated and applied at this stage. Then the economic analysis was performed by considering equipment, facilities and operation conditions provided by the process design part. Finally the environmental performances were assessed according to LCA principles. The main assumptions related to processes design and techno-economical part are primarily based on an NREL report (Humbird et al., 2011) that presents the process design and economics of cellulosic ethanol manufacturing from Corn Stover. NREL along with engineering companies provide data for operating conditions, equipment and raw material of $2 \mathrm{G}$ part. The assumptions are consistent with applicable best practices in engineering, construction, and operation. The biomass conversion efficiencies (i.e. cellulose to glucose or xylose to ethanol) are based on pilot-scale experiments carried out by the NREL researchers. The adaptation of these references to present models was mainly in the feedstock composition, capacity of the plant, rerouting of stream materials depending on the scenario, and assumption of no inhibitors depending on the pretreatment method. The project is assumed to start in 2020. The economic analysis is based on assumption that real prices will be the same in 2020 compared to those estimated by NREL. In the LCA it is assumed for the land use change that previously land use category for sugarcane plantation is a pasture. This influences directly on GHG emissions. For example the GHG emissions would have increased dramatically in case of tropical forest as previous land use category. Another assumption is the estimation of emissions from a combustion of different fuels at Cogeneration stage. The detailed combustion performance of bagasse and GHR are based on the approximation of wood chips combustion. The variability in combustion emissions can influence every impact category and requires further laboratory investigations. In conclusion the results of economic and LCA analyses depend on these assumptions. However the uncertainty of inputs in LCA are relatively higher, therefore to verify the obtained findings the uncertainty analyses were completed for LCA (Section 3.2).

\subsection{Definition and Aspen Plus simulation of the selected biorefineries}

Different configurations for the $1 \mathrm{G} 2 \mathrm{G}$ ethanol production, such as sugarcane handling, juice extraction, pretreatment, saccharification and fermentation, were defined and simulated in Aspen Plus v.8.6. The biorefinery scenarios were based on commercial scale sugar mill (SM-) or distillery (ED-) plants (Fig. 1). The former produces raw sugar and $\mathrm{C}$ molasses as direct products and $\mathrm{B}$ molasses that are converted into ethanol. A distillery plant only produces the juice used for the $1 \mathrm{G}$ ethanol part. The second generation part produces only ethanol (fermentation of both hexoses and pentoses, referred to -OF scenarios) or ethanol and C5-based syrup to feed animals (fermentation of only hexoses, defined as -FF scenarios). The integration involves a combined heat and power generation plant (CHP) to provide process energy requirements (Fig. 1). Electricity surplus is eventually sold to local utilities. The simulation of the integrated biorefinery in Aspen Plus V8.6 includes material, heat and electricity required to run the process. The material streams were technically defined as MIXCISLD ${ }^{1}$ involving conventional solids with no particle distribution. The components of the lignocellulosic material are not available in the Aspen Plus databank, so their properties and structures were modified as in the NREL model developed by Aden et al. (2002). Fibre components such as cellulose, hemicellulose and lignin were inserted as solids.

\subsection{1. $1 G$ Plant - ED- scenarios}

13,000 tons/day wet basis (w.b.) of sugarcane enter the factory (see composition in Table 1). Feedstock is first washed with 606.7 tons/h of water at $40^{\circ} \mathrm{C}$, which is recovered from the water stream after removal of dirt and impurities (Meyer et al., 2013). Extraction of sugars is carried out in the mill where sugarcane juice and bagasse are separated. The mechanical power needed for the mill is delivered by the cogeneration system. The technology considered for juice extraction involves a series of tandem roller mills with counter current juice flow to leach solubles (Gnansounou et al., 2005). Imbibition water ( 103.9 tons/h) is added to the last unit at $65^{\circ} \mathrm{C}$ in order to improve sucrose recovery in the final juice (Chen and Chou, 1993). Bagacillo particles are removed to be later used to compact the mud-cake. On this basis, the sugar extraction yield (i.e. the proportion of initial sugar present in the juice after extraction) reaches $94 \%$. The water and solubles represent about the $85 \%$ of the total fresh stem weight (Dias et al., 2011). Extracted juice is heated to near the boiling point $\left(103.5^{\circ} \mathrm{C}\right)$ and then lime $(1.2 \mathrm{~kg} \mathrm{CaO} /$ ton of cane) is added in form of milk at $15^{\circ}$ Baumé to raise the juice pH from 4.5 to 8 (Hugot, 1986; Dias et al., 2009). The process is known as defecation and is carried out to precipitate insoluble solids from the raw juice. The stream is then flashed and sent to the clarifier where the precipitate is separated. The settled solids from the clarifier are filtered and washed. Bagacillo is used as filtering medium (Jenkins, 2013). The final residue is known as cachaza (filter mud cake). The purified juice obtained after filtration is called thin juice containing $14 \%$ of sucrose with a purity of $94.2 \%$ (Chen and Chou, 1993). This juice in an ED- scenario is conveyed to the fermentation area of the $2 \mathrm{G}$ plant to be fermented.

\subsection{2. $1 G$ plant - SM- scenarios}

In this case, the thin juice is thickened in a multi-effect evaporator (Gnansounou et al., 2005). Low pressure (9.5 atm) steam produced in the boiler provides the energy for evaporation, and the condensed steam is returned as technical water. The thick juice leaves the evaporators at $60 \%$ sugar content (Olbrich, 2006). $2 \%$ of the thick juice is conveyed to the fermentation area in order to increase the ethanol yield, while the rest is destined to obtain sugar. White sugar is obtained by crystallization. The mixture of crystals (mainly sucrose) and the mother liquor (green syrup) are

\footnotetext{
${ }^{1}$ Depending on the physical state of the components, the stream class is defined in the Setup Specifications Global sheet of the Aspen Plus simulation. If the MIXCISLD stream class is selected, there are two valid substreams MIXED (vapour-liquid) and CISOLID (solids). After running the simulation, Aspen Plus automatically generates results for both substreams.
} 

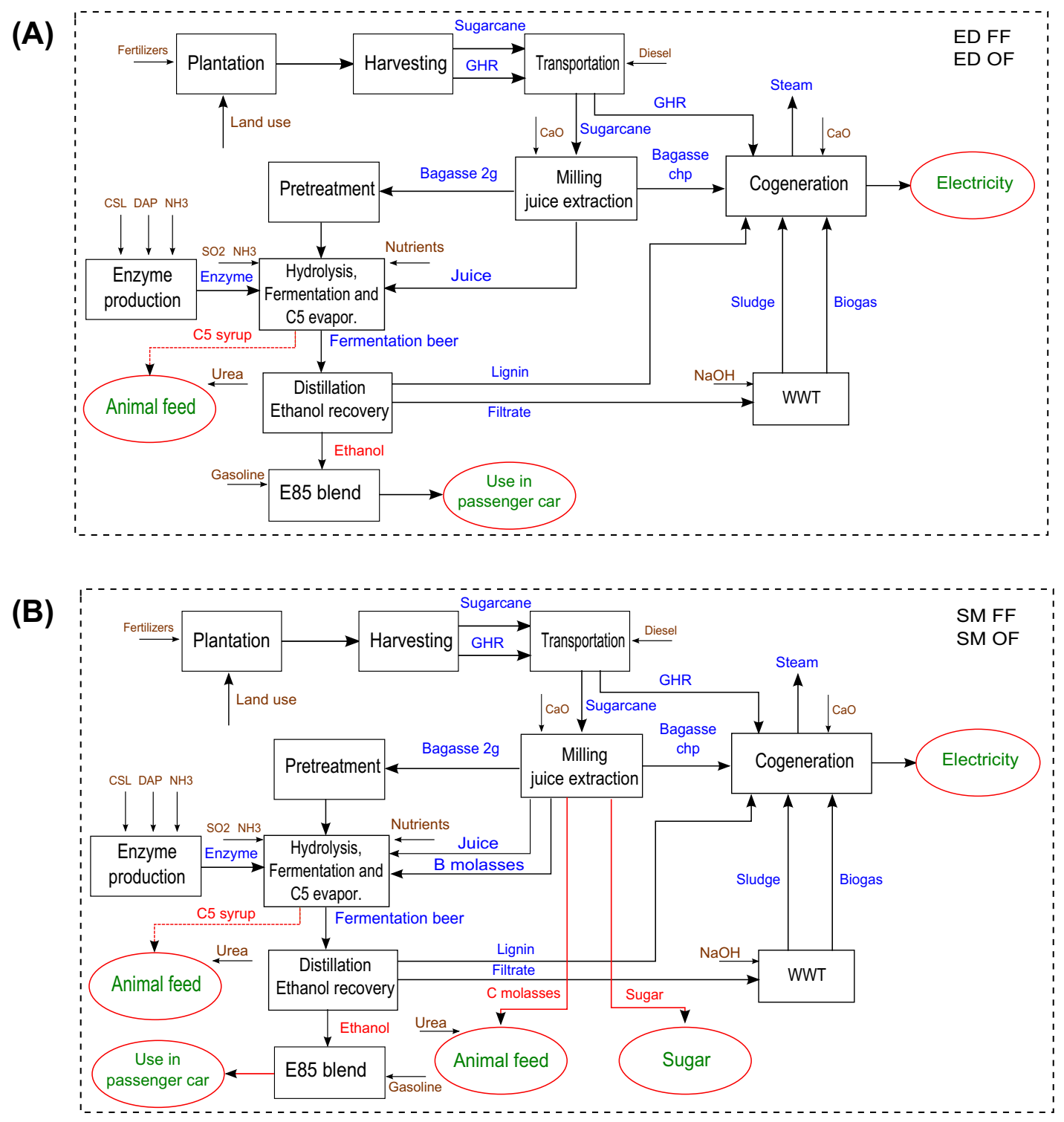

Fig. 1. System boundaries of ED FF and ED OF scenarios (A) and SM FF and SM OF scenarios (B).

Table 1

Composition of sugarcane, sugarcane bagasse and green harvesting residues (GHR).

\begin{tabular}{llll}
\hline & \multicolumn{2}{l}{ Weight percent $(\%)$} & \\
\cline { 2 - 4 } & Sugarcane & Sugarcane bagasse & GHR (in plant) \\
\hline $\mathrm{H}_{2} \mathrm{O}$ & 72 & 50 & 30 \\
Glucose & 1 & 0.1 & 0 \\
Sucrose & 14 & 3 & 0 \\
Extract & 1 & 2 & 6 \\
Cellulose & 6 & 20 & 25 \\
Galactan & 0.09 & 0.3 & 0.5 \\
Mannan & 0.04 & 0.15 & 0 \\
Xylan & 3 & 10 & 15 \\
Arabinan & 0.25 & 1 & 2 \\
Lignin & 3 & 12 & 15 \\
Acetate & 0 & 0 & 1 \\
Ash & 1 & 2 & 6 \\
\hline
\end{tabular}

separated in centrifuges where the sugar is washed with hot water. The wet sugar is dried, screened, and finally stored after cooling with high quality. The sugar yield is $722 \mathrm{~kg}$ per ton of sweet juice processed, and the efficiency (expressed as the ratio of white sugar produced to the initial sugar content) is over $72 \%$ (Gnansounou et al., 2005). The syrup from centrifuges known as molasses is passed through an additional boiling stage to extract some of the remaining sugars ( $\mathrm{B}$ and $\mathrm{C}$ molasses). As the concentration of non-sugars in the $\mathrm{C}$ molasses is high, no further crystallization is economically possible, so they are stored to be used by other industries. However B molasses are destined along with the $2 \%$ of thick juice to the fermentation area to be used for $1 \mathrm{G} 2 \mathrm{G}$ ethanol production.

\subsubsection{G Plant - OF and - FF scenarios}

Both 1G-plant scenarios (ED- and SM-) produce 1820 ton/day dry basis (d.b.) of sugarcane bagasse, where $60 \%$ is destined to the $2 \mathrm{G}$ pathway, while the remaining bagasse is sent to co-generation (see Fig. 1). Sugarcane bagasse is burnt along with residual solids and green harvesting residues (GHR). The composition of the feedstock is shown in Table 1. It is assumed that 2000 ton/day (d.b.) of GHR are available, where $50 \%$ are burnt in the cogeneration system and the remaining is left on the soil. The $2 \mathrm{G}$ plant can be divided into five areas: (1) feed handling, (2) pretreatment and solid-liquid 
separation, (3) pre-hydrolysis and simultaneous saccharification and fermentation (SSF), (4) distillation, and (5) combined power and heat generation.

1092 tons/day (d.b.) of sugarcane bagasse enters the (1) feed handling area to be transported and prepared for (2) pretreatment, where the lignocellulosic material is degraded. In this work, two pretreatment techniques were considered depending on the desirable products for the biorefinery: dilute acid (DA) for the -OF scenarios and liquid hot water (LHW) for the - FF ones. DA generates higher recovery yields of soluble xylose (C5) and improves enzymatic cellulose digestibility. However the accumulation of $\mathrm{H}^{+}$ accelerates the degradation of fermentable sugars possibly producing inhibitors. LHW is a chemical free process which hydrolyzes hemicellulose with steam and prevents inhibitor formation. It is less efficient than DA but offers more environmental advantages. LHW pretreatment was chosen for -FF scenarios as they involve food production from C5 sugars, then no further purification of the C5 syrup is required. The Aspen Plus model for -FF was based on the Integrated biomass utilisation system - IBUS base-case (Larsen et al., 2008, 2012) implemented in Inbicon A/S. In this case, bagasse is continuously soaked in processed water containing lactic acid recycled from distillation section. The stream is heated with steam to destroy the protecting lignin structure, and most of bagasse is converted into soluble sugars (xylose, mannose, arabinose and glucose) in the pretreatment reactor. The obtained hydrolyzate slurry containing around $30 \%$ of solids, is separated in a liquid and solid fraction as described by NREL (Aden et al., 2002). The liquid fraction contains C5 sugars from the hemicellulose and some cellulose not recovered in the solid fraction. No inhibitor production is assumed due to the relatively mild conditions of the process (Larsen et al., 2008). The liquid fraction enters in a three-effect evaporator train to produce a C5 syrup with 65\% of dry matter content. The solid fraction including more than $90 \%$ of the cellulose, the lignin originally presented in the cellulosic material, and some of the hemicelluloses, is ready for the following enzymatic hydrolysis (saccharification). In the -OF scenario, the pretreatment area was modelled adapting the NREL design (Humbird et al., 2011) to the case of sugarcane bagasse. DA is accompanied with an ammonia detoxification unit. After that, the whole pretreated hydrolyzate slurry is convoyed to saccharification.

Transporting pretreated solid fraction $(-\mathrm{FF})$ or pretreated hydrolyzate $(-\mathrm{OF})$ is challenging until the cellulose has been partially hydrolysed to decrease the viscosity, so prior to (3) saccharification, a liquefaction is performed using the cellulase enzyme produced in-situ (Humbird et al., 2011). The solid fraction is loaded into a continuous reactor at $20 \%$ water insoluble dry matter (DM) content. The fibre fraction consisting of approximately $50 \%$ cellulose is converted into a pumpable viscous liquid where $30-40 \%$ of the cellulose is hydrolysed into glucose (Larsen et al., 2008). After that, the saccharification continues in a batch reactor where a $90 \%$ conversion to glucose is achieved. The saccharified slurry is latterly mixed with the juice coming from the $1 \mathrm{G}$ plant and cooled to optimum temperature for fermentation (i.e. around $32{ }^{\circ} \mathrm{C}$ ). In the fermentation reactor, yeast is added to convert glucose ( $-\mathrm{FF}$ ) or glucose and xylose $(-\mathrm{OF})$ to ethanol. At the fermentation temperature, cellulases operate slower but still continue to degrade the remaining cellulose. The obtained fermentation broth includes an ethanol concentration close to $7 \%$, being ready to enter the beer distillation. The beer containing lignin and other soluble and insoluble solids is fed to (4) a steam distillation column operated at vacuum conditions, where a mixture of ethanol and water evaporates from the fibre fraction. In the models used, the beer column for distillation is a RadFrac column accomplished with 40 actual trays at $48 \%$ efficiency with the feed entering on the 13th tray from the top. After the beer column, stripped ethanol and water mixture is fed to a conventional rectification column. Ethanol product leaves rectification at a concentration close to $92.5 \%$. Product is further purified through vapour-phase molecular sieve absorption and the final stream consists of dehydrated ethanol at 99.4\%. Overhead from the beer column is fed to a water scrubber in order to remove ethanol from $\mathrm{CO}_{2}$. According to the Inbicon's technology, beer distillation bottoms are subject to a decantation process in order to separate lignin from the non-fermentable solubles of the stillage. In this work, the lignin separation step is modelled as a Pneumapress pressure filter, as in the NREL 2011's model. The stillage is separated in lignin cake and thin stillage. No enzyme recovery was considered. Thin stillage is conveyed to the wastewater treatment area (WWT) in which biogas and sludge are produced. Rectifier bottom (saturated water stream) is recirculated to the pretreatment step. The lignin cake is sent to the (5) cogeneration system along with the biogas and sludge from WWT, the not-processed sugarcane bagasse and the GHR. This area is modelled with a combustor, a boiler and a turbo-generator system. After satisfying plant's demand, the eventual excess electrical energy is sold to the grid.

\subsection{Methodology of techno-economic assessment}

Traditionally, techno-economic assessment of an integrated biorefinery can be performed using a net present value. However, such approach has few drawbacks in particular it does not appropriately consider the competition between alternative uses of intermediate products and feedstock. To overcome such limitations, in this work a value-based approach was used, firstly proposed by Gnansounou and Dauriat (2010). The application of that approach in this paper focuses on the price of the feedstock, under the assumption that its availability can be limited by competition between alternative uses. The main idea is to calculate the maximum-purchasing-price (MPP) of the biomass feedstock and then compare it with feedstock minimum-selling-price (MSP). $M P P$ is the highest price of feedstock that the biorefinery plant is willing to pay to be economically feasible, i.e. a lower price is possible but a higher price makes the biorefinery economically inefficient. MSP is the minimum price for biomass feedstock that can satisfy the supplier of biomass. The difference between the two values can be used as indicator of prospective economic performance $(P E P)$ of the evaluated project.

$P E P=M P P-M S P$

Therefore project with high PEP has better prospective economic feasibility than project with lower PEP. It should be noticed that MPP and MSP do not influence on each other. MPP is calculated by value-based method and depends on various techno-economic factors such as market prices of the biorefinery products, operation cost of the process, engineering techniques and value of intermediate streams. The method of calculation of MPP consists of several steps: (1) Unbundle the production chain into process stages (index $i$ ) (see biorefinery process in Fig. 1). (2) Fix the competitive target prices for the biorefinery products and operational features. (3) Calculate for every stage the annual recovery of capital (annuity) $A_{i}\left(\$ /\right.$ year) (Eq. (2)) and operation cost $O_{i}$ (\$/year). (4) Calculate the value of every intermediate product stream at every stage by use Eq. (3). (5) MPP is equal to the feedstock value at the final stage obtained by use Eq. (4)

$$
\begin{aligned}
& A_{i}=\frac{j(1+j)^{n}}{(1+j)^{n}-1} * \text {TIC}_{i} \\
& V_{i, k^{\prime}}=\frac{\sum_{i=1}\left(Q_{i} P_{i}+\sum_{k \in M} V_{i, k} m_{i, k}-O_{i}-A_{i}\right)}{m_{i, k^{\prime}}} \quad \forall k^{\prime} \in N
\end{aligned}
$$


$M P P=V_{i, k^{\prime}=\text { feedstock }}=\frac{\sum_{i=1}\left(Q_{i} P_{i}+\sum_{k \in M} V_{i, k} m_{i, k}-O_{i}-A_{i}\right)}{m_{i, k^{\prime}=\text { feedstock }}}$

where $T_{I C}$ is the total investment cost of process stage $i$ in $\$, j$ is an interest rate, index $k$ represents the intermediate product streams, $Q_{i}$ is the quantity of end-product at a process unit, ton/year $(\mathrm{kW} \mathrm{h}), P_{i}$ is the market price of an end-product leaving a process unit $i$ in $\$ /$ ton, ( $\$ / \mathrm{kW} \mathrm{h}), m_{i, k}$ is the flow rate of intermediate product streams in ton/year, $V_{i, k}$ is the value of the intermediate product streams in $\$ /$ ton, $M(i, k)$ is a set of streams $k$ leaving unit $i, N(i, k)$ is a set of inlet streams $k$ at unit $i$.

Eqs. (3) and (4) state that every stage is considered as economically independent (unbundling) and the sum of values of inlets streams equal the sum of values of outlet stream minus operation and investment costs. It should be noticed that for the calculation of MPP it is required to know the values of all intermediate streams that depend on capital investment, operation conditions and market prices of various co-products. The reference year for the calculations is 2010 however the operation of plant is proposed to start at 2020 year and all calculations are based on the assumption that real prices will be the same for start and reference years. The lifetime of the project is assumed to be 25 years and discount rate is $10 \%$. The investments for different scenarios were calculated using the investment data from NREL report for $2 G$ ethanol production (Humbird et al., 2011), and for $1 G$ and sugar mill from (Dias et al., 2011). To recalculate the cost of equipment to the reference year the Chemical Engineering Plant Cost Index (CEPCI, 2010) is employed. The costs of new equipment for different sizes were calculated using the exponential scaling expression:

New Cost $=$ Original Cost $\left(\frac{\text { New Size }}{\text { Original Size }}\right)^{n}$

where $n$ is the economy scaling factor that is 0.6 in the calculations.

Variable operating costs (OC) include materials and energy, waste handling, variable maintenance. Fixed operating costs (FOC) consider labour, insurance of equipment and annual fixed maintenance materials costs. OC and FOC were calculated based on the cost and price data at the NREL (Humbird et al., 2011) report. The prices of sugarcane (MSP) and GHR are 23.25 and $17.05 \$$ (Dias et al., 2011) respectively. The prices for ethanol, sugar, C molasses, C5 syrup and electricity are 760 (Dias et al., 2011), 320 (CEPEA, 2014), 36.3, 123.26 (USDA, 2014) \$/ton and 0 $.085 \$ / \mathrm{kW}$ h (Dias et al., 2011) respectively.

\subsection{Methodology of life cycle assessment}

The environmental performance of integrated biorefineries was evaluated according to the principles of Life Cycle Assessment (LCA). The LCA methodology quantifies the environmental impacts of products, processes or activities during their entire life cycle by considering the source of all inputs and the fate of all products and wastes. According to the ISO recommendation (ISO, 2006a,b) LCA consists of four stages: goal and scope definition, inventory analysis, impact assessment and interpretation. These stages with the key assumptions used in the present LCA analysis are described in detail in the next sections.

\subsubsection{Goal and scope definition}

In this phase, the system boundaries, reference system, functional unit, level of detail, the impact categories and the allocation method are identified. This is probably the most sensitive part of the LCA; final results can change drastically depending on the context-driven assumptions. The ultimate goal of the LCA in the present work is to evaluate the environmental performances of different integrated sugarcane-based biorefinery scenarios and compare them with the relevant reference systems. The technical details of scenarios are explained in Section 2.1. The system boundaries of ED- and SM- scenarios are presented in Fig. $1 \mathrm{~A}$ and $\mathrm{B}$ respectively. As can be observed there are different blocks in the system boundaries: cultivation and harvesting phases including land use, transportation block, full conversion pathway and final use of the products for specific services. For every scenario environmental impacts are evaluated several environmental categories: Climate change (in $\mathrm{kg}$ of $\mathrm{CO}_{2}$ eq.), Fossil depletion (in $\mathrm{kg}$ oil eq.), Human toxicity (in $\mathrm{kg}$ 1,4-DB eq.), Eutrophication ( $\mathrm{kg} \mathrm{P}$ eq.) and Fresh water ecotoxicity (kg 1,4-DB eq.). The functional unit (f.u.) for Well-to-Tank (WtT) LCA is 1 ton of sugarcane and for Tank-to-Wheel (WtW) f.u. is $1 \mathrm{~km}$ of car operation in the case of ethanol (vs. gasoline). In the next sections the definition of reference system, allocation method and land use change emissions are clarified.

2.4.1.1. Reference systems. The selection of relevant reference system is not a trivial task in the context of biorefinery since the various co-products that provide different services must be evaluated and compared. Furthermore the chosen reference system can significantly influence the final interpretation of the results and therefore the decision of a viability of the whole system. The evaluated sugarcane-based integrated biorefineries can provide up to five products: ethanol, sugar, C molasses, C5 syrup and electricity. In the present LCA it is proposed to avoid the common practice of comparing final products and it is suggested to use relevant services provided by them. In general there are four services considered for analysis: travel distance by car operation (WtW LCA for ethanol product), animal feed supplement service (for C5 syrup and $C$ molasses), sugar at sugarcane mill and electricity at the grid. The simplified systems definitions and main assumptions for reference and studied systems associated with evaluated scenarios can be seen at Figs. 2 and 3.

To compare the ethanol with fossil fuel travelled distance service is employed, in particular the operation of a medium passenger cars using E85 ethanol blend (system under study) was compared with gasoline EURO 4 (reference system). The methodology developed by Gnansounou et al. (2010) was used to estimate the fuel efficiency for ethanol in the blend and consequently the well-to-wheel GHG emissions of the bioethanol for $1 \mathrm{~km}$ travelled.

$F E_{\text {biofuel }}=\frac{B F_{\text {biofuel }} F E_{\text {fuelblend }}}{1-\left(1-B F_{\text {biofuel }}\right) \frac{F E_{\text {fuelblend }}}{F E_{\text {fossilfuel }}}}$

where $F E_{\text {biofuel }}, F E_{\text {fuelblend, }} F E_{\text {fossilfuel }}$ are fuel efficiency of biofuel (bioethanol in our case), fuel blend and fossil fuel (gasoline) respectively, in $1 / \mathrm{km}$. $B F_{\text {biofuel }}$ is a blend factor that is 0.85 for E85 blend. The Brazilian average (theoretical) fuel efficiency of gasoline for the new passenger car is $7.48 \mathrm{l} / 100 \mathrm{~km}$. For the $85 \%$ of ethanol blended with gasoline the increased fuel consumption is around $35 \%$ in comparing with (theoretical) pure gasoline. In Eq. (6) the fuel efficiency of ethanol in fuel blend that is estimated as 10.76 1/100 km for E85. Furthermore fuel efficiency allows calculating the travel distance of operation car that consumes ethanol obtained from particular biorefinery per certain time.

The sugar from biorefinery was compared with the same amount of sugar (in $\mathrm{kg}$ ) produced at sugar mill from sugarcane in Brazil region. Even being similar products these two sugars differ from the production chains. To evaluate environmental impacts of $\mathrm{C}$ molasses and C5 syrup it is included animal feed service in the reference system (in $\mathrm{kg}$ ). The reference cattle feed supplement consist of $8 \%$ of urea that is a protein source and $92 \%$ of molasses with dry matter (DM) content of $73 \%$. To provide the same service for molasses and C5 syrup it is calculated their feed supplement equivalent based on DM content of C5 syrup and molasses. The reference molasses (DM 73\%) is produced at sugar mill from 
(A)
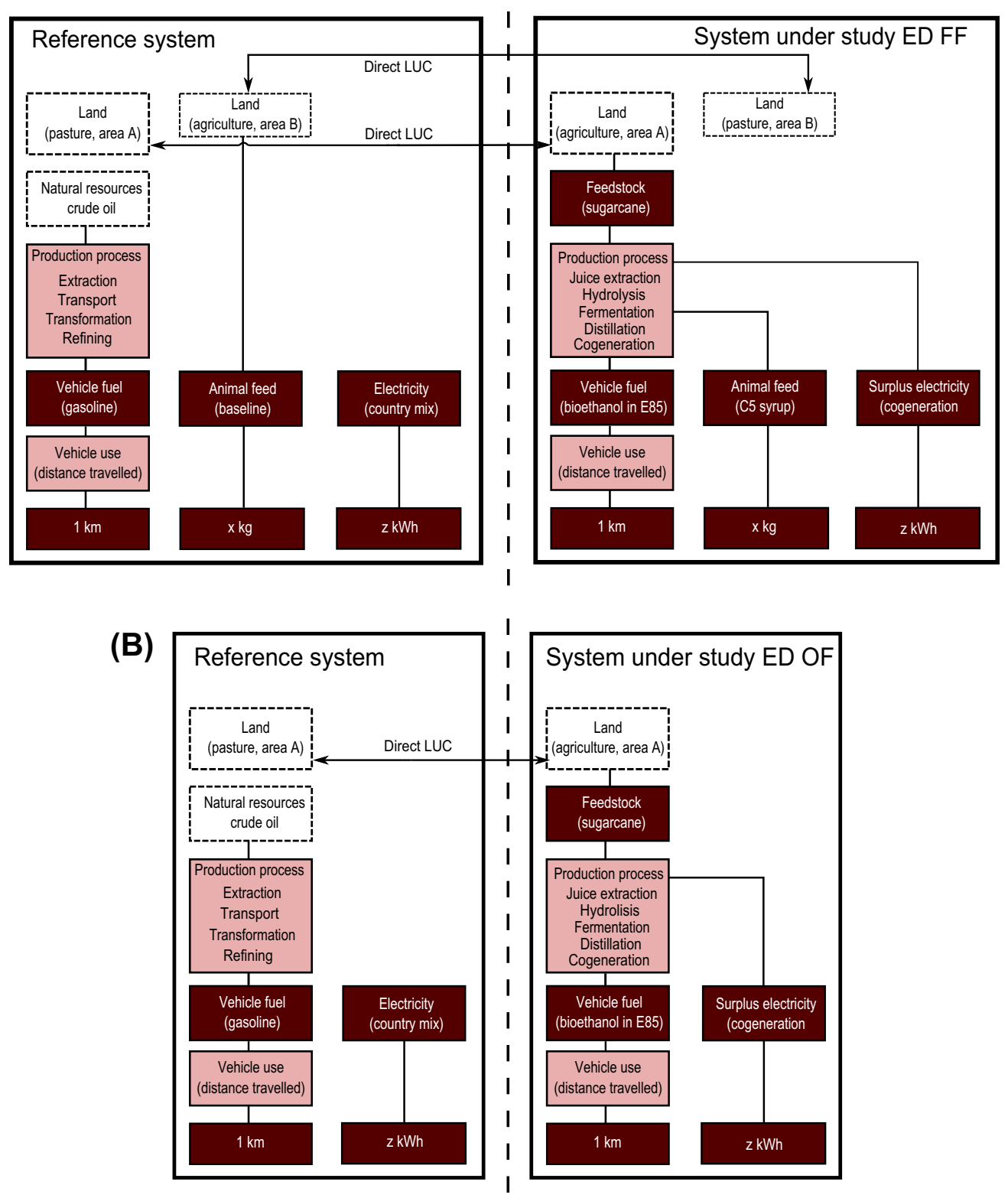

Fig. 2. System definition and boundaries (from reference system to system studied) for ED FF (A) and ED OF (B) scenarios.

sugarcane in Brazil. Finally, Brazil mix electricity at the electrical grid (in $\mathrm{kW} \mathrm{h}$ ) is chosen as reference to the surplus electricity generated at biorefinery. As can be seen from Figs. 2 and 3 the travelled distance and electricity are presented at every reference systems (RSs), animal feed is included in RSs of ED FF and SM FF, production of sugar is present in RSs of SM FF and SM OF scenarios. The land use is included in all reference systems in the present analysis.

2.4.1.2. Direct Land use changes. The Land-use is an important factor in the analysis of the bioenergy systems since the source of energy for such systems i.e. biomass is produced on the land. Here it is considered in reference system that the lands where the feedstock for the animal feed and sugars were initially produced are turned into pasture. Similarly, it is considered that sugarcane in the system under study is grown on land that was initially native pasture. Thus the amount of land-use in reference system and system under study was balanced. To facilitate calculations the land-use is transferred from reference system to system under study with an opposite sign (Gnansounou et al., 2010). Such land-use change may lead to change in carbon pools of soil and vegetation part depending on cultivation practices (e.g. tillage). The GHG emission caused by such carbon stock change is included in the GHG emission and calculated according to IPCC methodology (IPCC, 2006).

$\Delta C_{\text {change }}=\Delta C_{\text {soil }}+\Delta C_{\text {biomass }}=\Delta C_{\text {soil }}+C_{\text {biomass }}^{\text {sugarcane }}-C_{\text {biomass }}^{\text {pasture }}$

where $\Delta C_{\text {change }}$ is a total annual carbon stock changes of converted land, tonC/ha/year; $\Delta C_{\text {soil }}$ is a carbon stock changes in soil, tonC/ha/year; $C_{\text {biomass }}^{\text {sugarcane }}$ is a carbon stock changes in biomass of sugarcane, tonC/ha/year; $C_{\text {biomass }}^{\text {pasture }}$ represents carbon stock changes in biomass of pasture, tonC/ha/year. The summary of the land categories and carbon stocks is presented in Appendix A (Table A.1). $\Delta C_{\text {soil }}$ were obtained using IPCC tool ( -0.82 tonC/ha/year). $C_{\text {biomass }}^{\text {sugarcane }}$ and $C_{\text {biomass }}^{\text {pasture }}$ are respectively 11.88 and 10.14 tonC/ha/year, such data where taken from literature (Dias Paes and Marin, 2011). Eq. (7) calculates total annual carbon stock changes of converted land. In the 
(A)

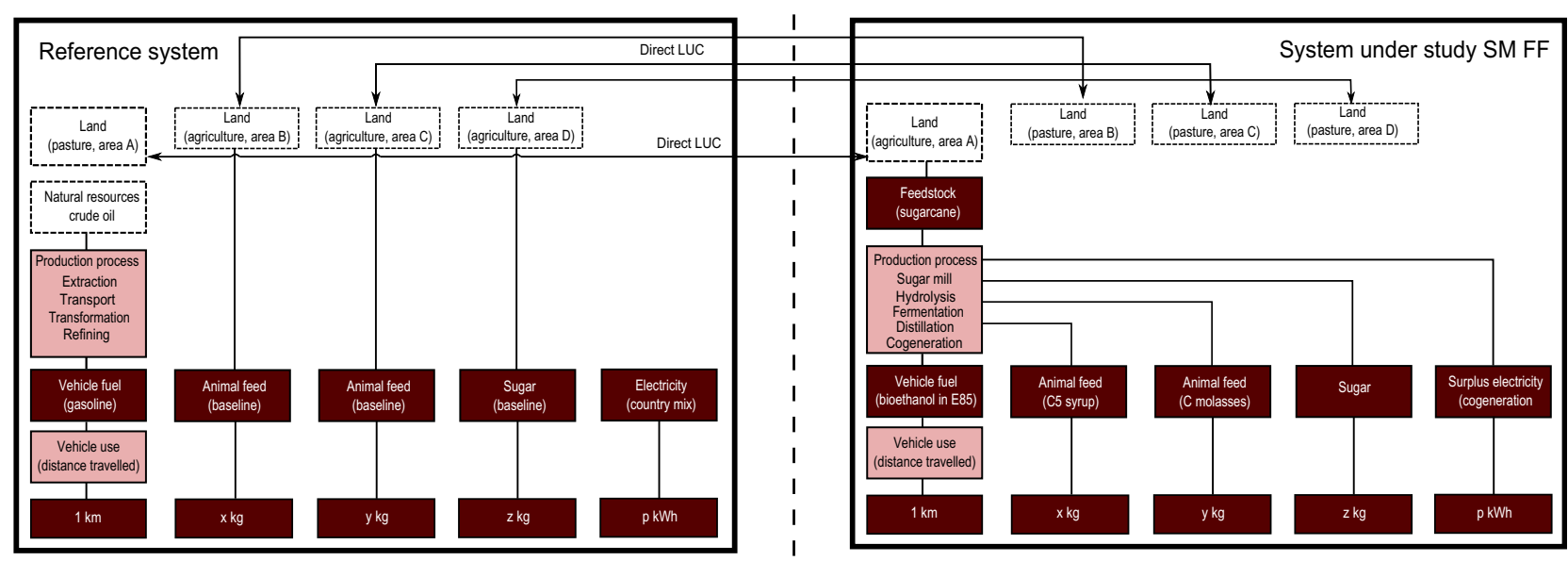

(B)

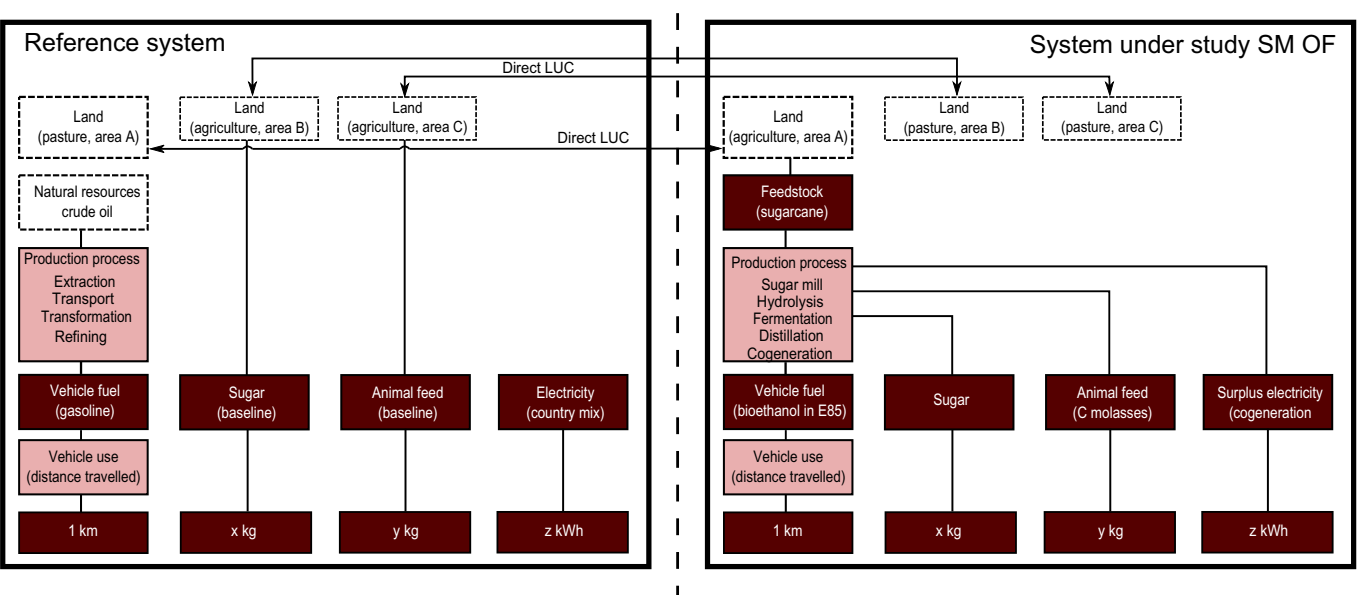

Fig. 3. System definition and boundaries (from reference system to system studied) for SM FF (A) and SM OF (B) scenarios.

conditions assumed in the study $\Delta C_{\text {change }}$ equals 0.92 tonC/ha/year. After multiplying $\Delta C_{\text {change }}$ by $44 / 12$ parameter it was finally obtained 3.73 ton $\mathrm{CO}_{2} /$ ha/year. That means 3.73 ton of $\mathrm{CO}_{2}$ every year per 1 ha of land can be sequestered from atmosphere for the land converted from native pasture to sugarcane plantation in the assumed conditions.

2.4.1.3. Allocation method. To perform the LCA the intermediate products at each stage require an allocation.

The allocation methods can significantly affect the final results of the analysis. Several allocation methods are discussed in literature (Gnansounou et al., 2010) however there is no single methodology that can be assumed as the best allocation practice and the choice of the allocation in particular multiprocessing system depends on the context and decision maker's preferences. In this study it is employed value-based economic allocation since one of the most important indicators of biorefinery is the economic benefit.

\subsubsection{Inventory analysis, impact assessment and interpretation}

Life cycle inventory ( $\mathrm{LCI}$ ) is the methodology step that provides the inputs and outputs of materials and energy associated with the process or products, which are required to perform the environmental impact calculations. In this study the inventories of the sugarcane biorefinery process were based on the computer simulations of the process performed in Aspen Plus v. 8.6 and described in Sections 2.1. For agricultural stage the average data for Brazil from Ecoinvent 3.0 database were employed. Inventory analysis is a next step aimed at evaluating the significance of potential environmental impacts based on the LCI flow results. The software package SimaPro v8.0 and Recipe midpoint (E) methodology were used as tools for the environmental impact assessment. Finally in the interpretation step the results were analysed and sets of conclusions and recommendations were formulated.

\section{Results of the comparison of the selected biorefineries}

\subsection{Process simulation results}

Table 2 shows the main results obtained by process simulation for the four different scenarios considered in the present analysis (Section 2.1). The highest yield of ethanol (92 kg ethanol/ton SC) is obviously obtained in the scenario where only biofuel is produced, while the lowest amount (24 kg ethanol/ton SC) corresponds to the SM-FF scenario where co-products such as raw sugar, $C$ molasses and C5 syrup are obtained along with the ethanol. The energy self-sufficiency of the processes is achieved for all the considered scenarios; they produce surplus electricity. As the amount of GHR and bagasse sent to co-generation is fixed, the electricity production depends on both electricity and heat requirements in the process. Distillery plants require more energy than sugar mills. Therefore the excess of electricity produced in ED- scenarios ( $25 \mathrm{~kW} \mathrm{h/ton} \mathrm{SC} \mathrm{for} \mathrm{ED-OF)} \mathrm{is} \mathrm{lower} \mathrm{than} \mathrm{in} \mathrm{SM-}$ scenarios (60 kW h/ton SC for SM-OF). The electricity consumption of the $1 \mathrm{G}$ part is due to the milling and juice treatment processes that are common to both ED and SM scenarios. However fermenting and distiling the juice involve a greater steam demand than 
Table 2

Results process simulation of the $1 \mathrm{G}-2 \mathrm{G}$ plant.

\begin{tabular}{|c|c|c|c|c|c|c|c|}
\hline & $\begin{array}{l}\text { Ethanol yield } \\
\text { kg/ton SC (w.b.) }\end{array}$ & $\begin{array}{l}\text { Syrup yield } \\
\text { kg/ton SC (w.b.) }\end{array}$ & $\begin{array}{l}\text { Sugar } \\
\text { kg/ton SC (w.b.) }\end{array}$ & $\begin{array}{l}\text { C molasses } \\
\mathrm{kg} / \text { ton SC (w.b.) }\end{array}$ & $\begin{array}{l}\text { Total electricity } \\
\text { kW h/ton SC (w.b.) }\end{array}$ & $\begin{array}{l}\text { Surplus electricity } \\
\text { kW h/ton SC (w.b.) }\end{array}$ & $\begin{array}{l}\text { Steam demand } \\
\text { GJ/ton SC (w.b) }\end{array}$ \\
\hline ED-FF & 82 & 27 & - & - & 120 & 13 & 1.63 \\
\hline ED-OF & 92 & - & - & - & 124 & 25 & 1.26 \\
\hline SM-FF & 24 & 27 & 96 & 103 & 91 & 48 & 1.46 \\
\hline SM-OF & 34 & - & 96 & 103 & 95 & 60 & 1.09 \\
\hline
\end{tabular}

extracting the crystallized sugar from the juice and fermenting and distiling a more concentrated substrate such as B molasses in the SM scenarios (Fig. 4). As can be seen on the graph, the steam demand in combined $1 \mathrm{G}$ - distillation areas is higher in distilleries (452 GJ/h in ED-FF) than in the sugar mill configurations $(376 \mathrm{GJ} / \mathrm{h}$ in SM-FF).

\subsection{Techno-economic analysis}

The techno-economic analysis was performed by economic-value approach that depends on market prices of the biorefinery products, operation and capital costs of the process, engineering techniques and value of intermediate streams (see Section 2.1). The maximum-purchasing-price (MPP) for feedstock, prospective-economic-performance $(P E P)$ indicators and allocation factors of process streams were calculated for every scenario. It is important to note that obtained results are dependent to assumptions made in the analysis (Section 2).

The main results from process simulation and economic analysis are summarised at Table 3. As can be observed all scenarios show economic efficiency and provide positive PEP. It means that $\operatorname{MPP}(35.09,39.52,30.37,37.95$ in $\$ /$ ton SC for ED FF, ED OF, SM FF and SM OF scenarios respectively) for sugarcane from biorefinery plants is higher than MSP (23.25 $\$$ /ton SC) from the market for all scenarios. However there are few differences between various scenarios. Analysing the results it can be concluded that the economic performance of different biorefineries with fixed biomass feedstock is sensitive to the range of final products (i.e. level of integration) and, in particularly, to ethanol production. Scenario ED OF which presents the production of only 1-2 g ethanol and surplus electricity shows the highest PEP (16.27 \$/ton SC), while the lowest PEP (7.12 \$/ton SC) is provided by SM FF scenario which produces five types of different products and represents the highest level of sugar mill - ethanol distillery integration. In addition we can notice that $\mathrm{C} 5$ syrup production does not show great economic performance. For example scenarios SM FF and SM OF produce the same amount of sugar and molasses but SM FF makes C5 syrup at the expense of ethanol production (Table 3 ). It leads the significant changes in MPP (30.37\$/ton SC for SM FF and $37.95 \$ /$ ton SC for SM OF). In could be noticed that ethanol production has the biggest influence on the economic performance however the comparison between scenario ED FF and scenario SM OF shows that production of additional outputs like sugar and $C$ molasses yields the higher PEP. That can be explained by the high market prices of sugar and C molasses products and that TCI (total capital investment) is increased with growing of ethanol production (Table 3). Therefore economic performance is sensitive to the extent of $1 \mathrm{G}-2 \mathrm{G}$ integration. However it is not the unique parameter that influences the prospective economic performance of the potential biorefinery. Finally the allocation factors of intermediate streams required for LCA were calculated according to value based approach. The results are presented at Table 4 . Analysing the results, it can be predicted the high importance of ethanol and sugar production for LCA analysis and less importance of $\mathrm{C}$ molasses and $\mathrm{C} 5$ syrup.

\subsection{Life cycle analysis}

The results of LCA for different biorefinery scenarios and several environmental impacts are presented in Figs. 5 and 6. Fig. 5A shows results for climate change impact and quantifies the amount of GHG emissions in $\mathrm{kg}$ of $\mathrm{CO}_{2}$ eq. per 1 ton of sugarcane. As it can be observed impacts obtained by integrated biorefinery scenarios are lower than impacts provided by associated reference systems - RSs. In particular the results for various biorefinery scenarios and associated RS are the following - ED FF: 105 and 350, ED OF: 110 and 385, SM FF: 77 and 176, SM OF: 90 and 220, $\mathrm{kg} \mathrm{CO}_{2}$ per 1 ton of sugarcane. It can be noticed that the travelled distance service provides the greatest contribution in every reference system and in every scenario except SM FF (where the ethanol production is the lowest). More precisely these contributions are $94 \%, 99 \%, 40 \%$ and $50 \%$ for ED FF, ED OF, SM FF and SM OF scenarios respectively. That can be explained by the economic allocations (Table 4) that gives high allocation factor to ethanol production.

Comparing the absolute performance of the biorefineries it can be observed that climate change impact for ED FF and ED OF scenarios is higher than impacts for SM FF and SM OF ones. On the one hand it can prove that diversification of the biorefinery products and intensification of integration may lead to a better mitigation of GHG emissions and therefore increase the environmental sustainability of the whole plant, depending on the products that are involved. On the other hand, in the work the difference is mainly explained by the lowest ethanol production of SM FF and SM OF plants (Table 3) and the lower GHG emission factors of the coproducts. However comparing the relative performances i.e. extend of impact reduction between the RS and the corresponding bio-refinery, it can be observed that ED FF and ED OF show higher reduction of impact (70\% and 71\%) than SM FF and SM OF (56\% and 59\% respectively). This is due to the higher proximity between the co-products in the latter biorefineries and their counterparts in the RSs.

Another important impact category is the Fossil depletion (Fig. 5 (B)). The absolute results for biorefineries and associated RSs (in kg oil eq. per 1 ton $\mathrm{SC}$ ) and relative impact reduction (in\%) are following ED FF: 46 and 103 (55\%), ED OF: 48 and 112 (57\%), SM FF: 28 and 57 (51\%), SM OF: 33 and 67 (51\%). It can be noticed the main conclusions are similar to the climate change assessment: the total fossil depletion of all evaluated biorefinery scenarios are significantly lower than impacts provided by RSs; the greatest contribution in environmental performance is provided by fuel ethanol (except of SM FF); scenarios with a high extent of integration comprising sugar mills and ethanol distillery have lower absolute impact (SM FF and SM OF) than only ethanol distillery biorefineries (ED FF and ED OF), however latter scenarios show higher reduction of impact than SM FF and SM OF scenarios. In general such results are not a surprise because the biorefinery systems consume significantly less fossil resources in comparison with industrial reference process based on non-renewable resources and gasoline. Results of Human toxicity impact that represents the assessment of toxic effects of substances on humans show other trend in impacts behaviour (Fig. 6A). Results provided 


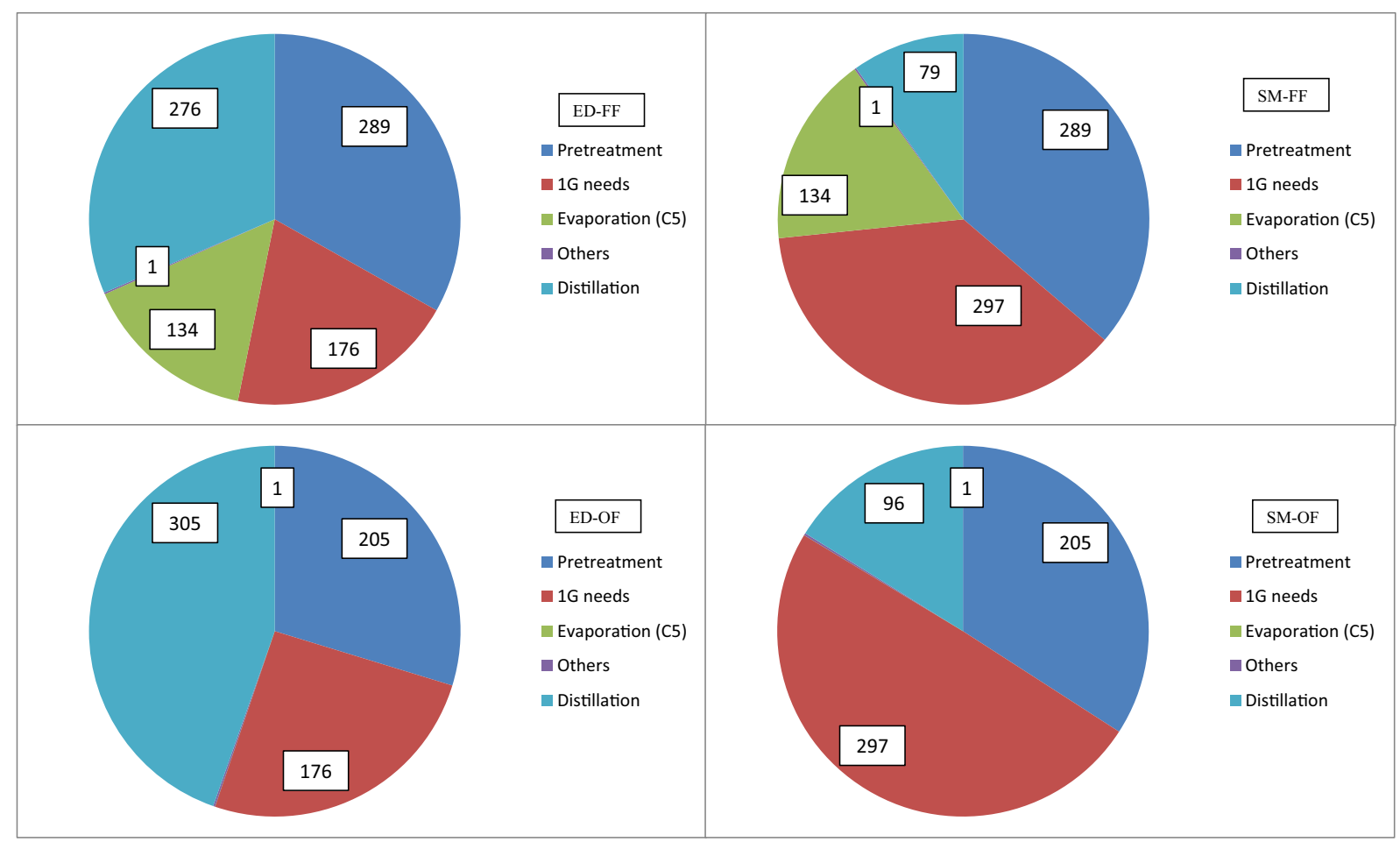

Fig. 4. Heat demand distribution in GJ/h for the options evaluated. Ethanol Distillery (ED) and Sugar Mill (SM) producing Only Fuel (OF) or Feed and Fuel (FF).

Table 3

Data and results for economic analysis.

\begin{tabular}{llllll}
\hline Scenarios & & ED FF & ED OF & SM FF & SM OF \\
\hline Ethanol & ton/year & 320,070 & 359,063 & 94,392 & 133,235 \\
C5 Syrup & ton/year & 106,400 & 0 & 106,229 & 0 \\
Sugar & ton/year & 0 & 0 & 372,468 & 372,468 \\
C molasse & ton/year & 0 & 0 & 402,239 & 402,239 \\
Electricity & GW h/year & 53 & 97 & 192 & 394 \\
$\mathrm{TCl}^{\mathrm{a}}$ & $\mathrm{M} \$ / \mathrm{y}$ & 794 & 798 & 750 & 760 \\
$\mathrm{OC}^{\mathrm{b}}$ & $\mathrm{M} \$ / \mathrm{y}$ & 14 & 16 & 12 & 15 \\
$\mathrm{FOC}^{\mathrm{c}}$ & $\mathrm{M} \$ / \mathrm{y}$ & 15 & 15 & 14 & 15 \\
$\mathrm{MPP}^{\mathrm{d}}$ & $\$ /$ ton & 35.09 & 39.52 & 30.37 & 37.95 \\
$\mathrm{MSP}^{\mathrm{e}}$ & $\$ /$ ton & 23.25 & 23.25 & 23.25 & 23.25 \\
$\mathrm{PEP}^{\mathrm{f}}$ & $\$ /$ ton & 11.84 & 16.27 & 7.12 & 14.70 \\
\hline
\end{tabular}

a $\mathrm{TCI}$ - total capital investment.

b OC - operation cost.

c FOC - fixed operation cost.

d MPP - maximum purchasing price for feedstock (sugarcane).

e $M S P$ - minimum selling prices for feedstock (sugarcane).

${ }^{\mathrm{f}} \mathrm{PEP}$ - prospective economic performance.

by biorefineries are close or even higher than RSs impacts. In particular numerical results for biorefinery and associated RSs respectively are following (in kg 1,4-DB eq.) ED FF: 4616 and 4339, ED OF: 4235 and 3960, SM FF: 2181 and 2247, SM OF: 1759 and 1796. Similar results can be observed for Freshwater ecotoxicity (Fig. 6B) and Freshwater eutrophication (Fig. 6C) that are important impact categories, especially in Brazilian context due to the great amount of aquatic resources in this country. However it could be noticed that impacts provided by SM- scenarios are lower than impacts from RSs. Such results can be explained by the fact that ethanol distilleries consume high amount of chemicals compared to fossil fuels. In addition production of sugarcane requires huge water resources including irrigated water. However that result is less applying to the SM scenarios where
Table 4

Allocation factors for full integration biorefinery process.

\begin{tabular}{clllll}
\hline & & ED FF & ED OF & SM FF & SM OF \\
\hline Harvesting & Sugarcane & 0.9499 & 0.9548 & 0.9456 & 0.9536 \\
& GHR & 0.0501 & 0.0452 & 0.0544 & 0.0464 \\
Milling, juice & Bagasse chp & 0.0896 & 0.0716 & 0.0193 & 0.0199 \\
& & & & & \\
& Bagasse 2g & 0.0216 & 0.0985 & 0.0156 & 0.0666 \\
& Juice & 0.8889 & 0.8298 & 0.0849 & 0.0997 \\
& Sugar & 0.0000 & 0.0000 & 0.7842 & 0.7249 \\
Hydrolysis and & Molasses & 0.0000 & 0.0000 & 0.0961 & 0.0888 \\
fermentation & Fermentation & 0.9382 & 1.0000 & 0.7416 & 1.0000 \\
& beer & & & & \\
Distilation and & Syrup & 0.0618 & 0.0000 & 0.2584 & 0.0000 \\
ethanol recovery & Ethanol & 0.8834 & 0.8931 & 0.7456 & 0.8035 \\
& & & & & \\
& Lignin & 0.0207 & 0.0134 & 0.0105 & 0.0067 \\
WWT & Filtrate & 0.0958 & 0.0934 & 0.2439 & 0.1899 \\
& Biogas & 0.3348 & 0.4862 & 0.3190 & 0.5307 \\
Cogeneration & Sludge & 0.6652 & 0.5138 & 0.6810 & 0.4693 \\
& Electricity & 0.5822 & 0.6656 & 0.7205 & 0.8245 \\
& Eteam & 0.4178 & 0.3344 & 0.2795 & 0.1755 \\
\hline
\end{tabular}

cultivation of sugarcane is also required in the reference system. Therefore despite the fact that interpretation of results is sensitive to RSs, the configurations with high level of $1 \mathrm{G}-2 \mathrm{G}$ - sugar mill integration lead to reduction of environmental impacts in different categories.

Bearing in mind that the present analysis is based on several assumptions and data collected from literature sources uncertainty analysis by Monte Carlo method within SimaPro v. 8.0 was made to check the results robustness. According to the recommendation from SimaPro tutorial (Goedkoop et al., 2013) lognormal distribution was assumed. The results show that for all scenarios Climate change impact obtained from biorefinery is lower than impact from associated RS in 99-100\% cases, for Fuel depletion impact 
(A)

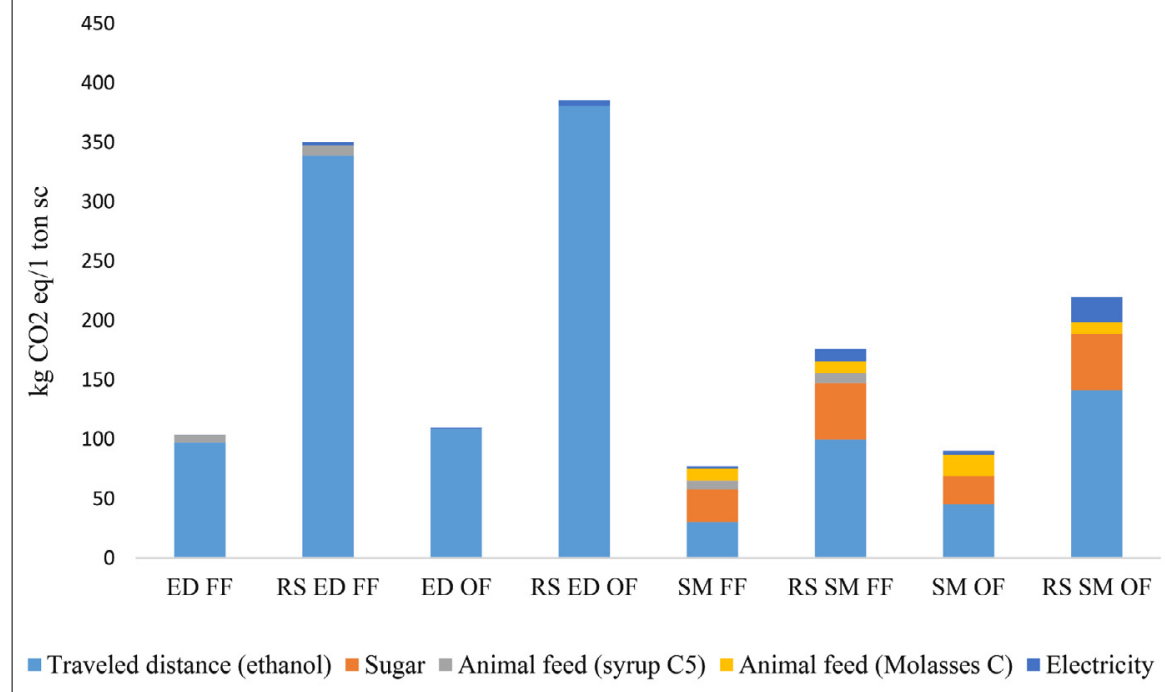

(B)

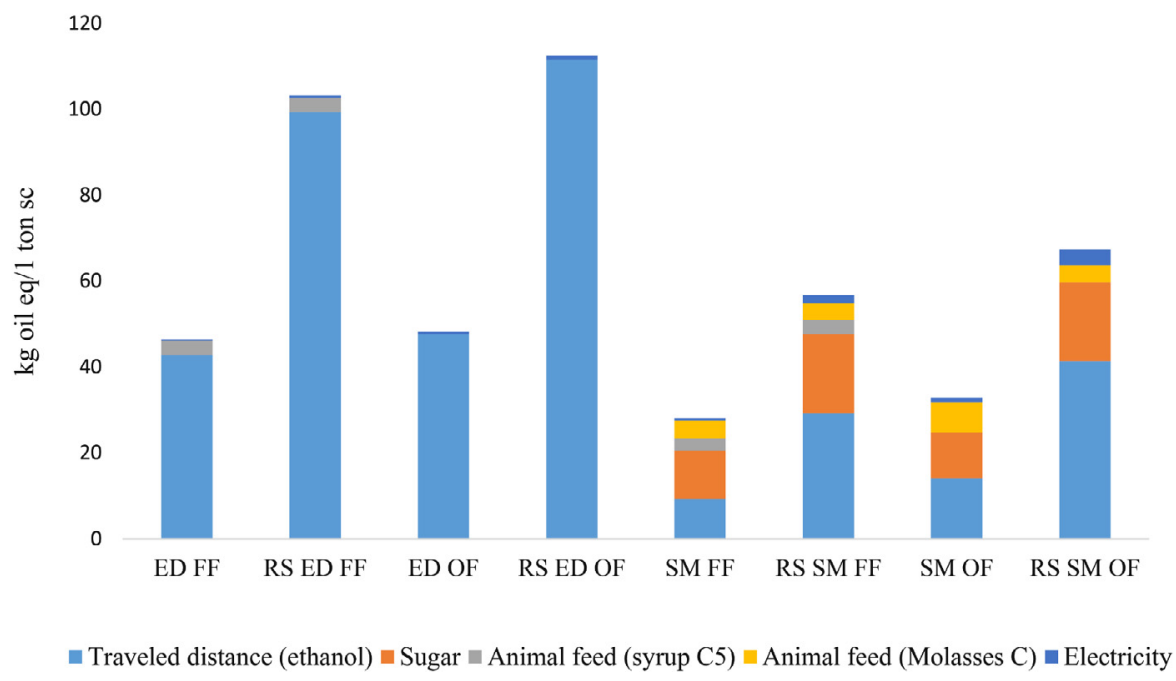

Fig. 5. Results of LCA for climate change (A) and Fossil depletion (B) impacts.

such range is $95-100 \%$. Analysis for Human toxicity and Freshwater ecotoxicity impacts show close results where biorefinery is environmentally friendlier than RS in $45-55 \%$ of Monte Carlo runs. Finally the Freshwater eutrophication impacts of biorefinery are lower than ones from RS for SM- scenarios (83\% for SM FF and $77 \%$ for SM OF) and higher for ED-configurations (60\% for ED FF and $62 \%$ for ED OF). Comparison results of uncertainty analysis and relative results of LCA shows that they are consistent and therefore can be recognised with high extent of credibility.

Analysing economic and LCA results simultaneously it can be noticed that the best economic scenario (ED OF) has the highest absolute environmental impact and opposite, the scenario SM FF with worst PEP has the lowest absolute impacts. That is explained by the largest production of ethanol in the ED OF and lowest in SM FF configurations (Table 3 ). However it is not an obvious trend that better economy associates with worse absolute environmental performance. For example, scenario SM OF has good results for both indicators: PEP (14.7\$/ton SC) and absolute environmental impacts (e.g. $90 \mathrm{~kg} \mathrm{CO} 2 \mathrm{eq} /$ ton for climate change).
In general it can be concluded that integrated biorefinery could make strong sense in terms of economic feasibility, mitigation of Climate change and decrease in Fossil depletion. However it could show lower improvements in Human toxicity, Freshwater ecotoxicity and Freshwater eutrophication compared to the reference systems that were considered in this study. Nevertheless that is not due to the integrated biorefineries themselves but on the fact that in the system under study, bioethanol production implying cultivation of land (1G component) is compared to a reference system where only gasoline is equivalently produced without land cultivation. Furthermore, as the production of petroleum oil is massive compared to ethanol, the impacts on toxicity and eutrophication may be minored in the $\mathrm{LCI}$ when divided by the quantity produced (scale effect). In additional it is noteworthy mentioning that integrating $2 \mathrm{G}$ based on conversion of agricultural residues to $1 \mathrm{G}$ contributes significantly to reduce environmental impacts in comparison with the conventional ethanol industry. On the other hand, there is an economic cross-subsidy between the $1 \mathrm{G}$ and the $2 \mathrm{G}$. 


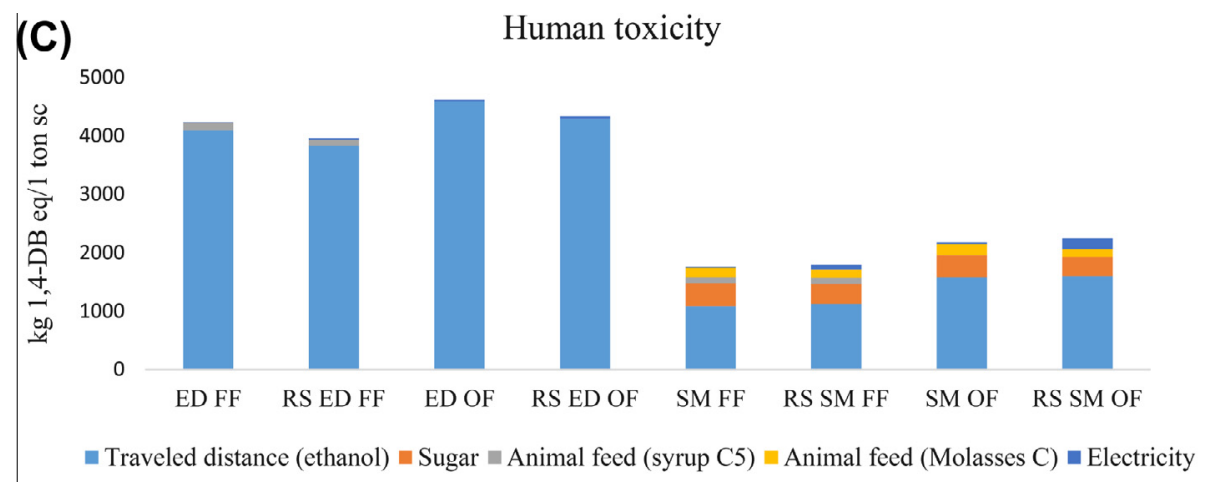

(D) Freshwater ecotoxicity

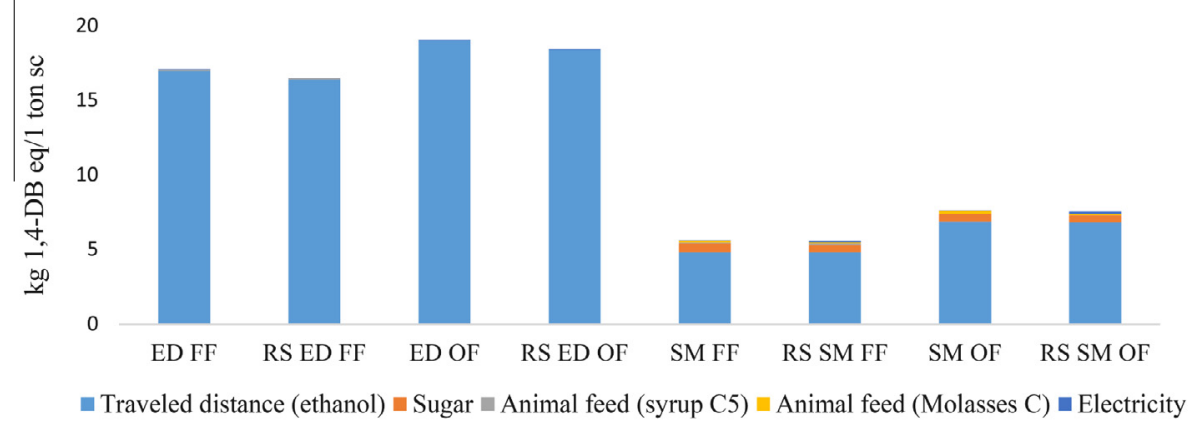

(E)

Freshwater eutrophication

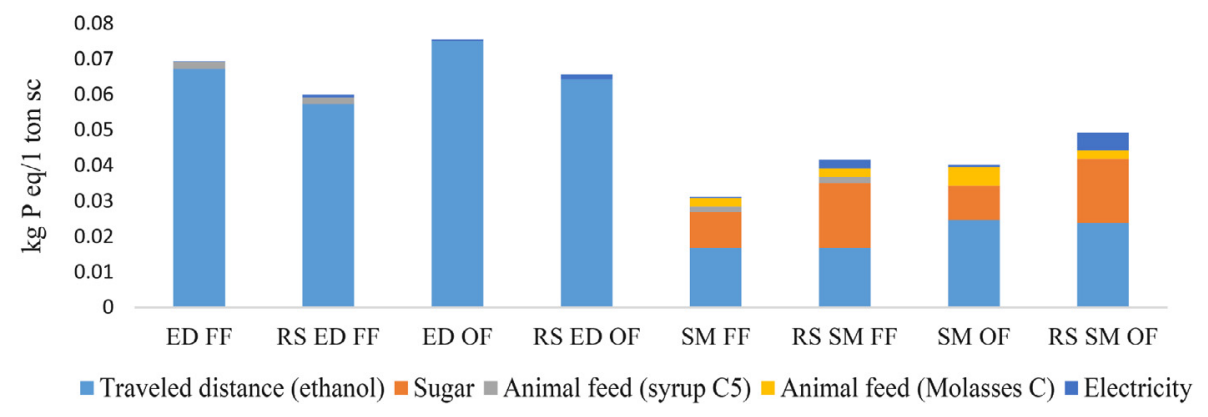

Fig. 6. Results of LCA for human toxicity (A), freshwater ecotoxicity (B) and freshwater eutrophication (C) impacts.

\section{Conclusion}

Several integrated sugarcane-based biorefinery scenarios in Brazilian context were investigated according to value based economic and LCA principles. All evaluated scenarios demonstrate positive values of Climate change and Fossil depletion reduction as compared to the reference systems. However it shows less efficiency in Human toxicity, Freshwater ecotoxicity and Freshwater eutrophication impacts for "only fuels" scenarios. The scenario with the largest ethanol production shows the best economic configuration while scenario with five products presents the lowest absolute environmental impact. Integration of residues based $2 \mathrm{G}$ to $1 \mathrm{G}$ leads to positive environmental impacts compared to $1 \mathrm{G}$ conventional industry but proves to be more expensive.

\section{Acknowledgements}

This work was co-funded by the European Commission in the framework of EU-Brazil ProEthanol2G Project - "Integration of
Biology and Engineering into an Economical and Energy-Efficient 2G Bioethanol Biorefinery" (FP7-251151) and by the Swiss National Foundation in the framework of ENERCHEMS project "Utilising Agricultural Residue from Sugarcane Harvesting for the Production of Bio-Energy and Chemicals in Biorefinery".

\section{Appendix A. Supplementary material}

Supplementary data associated with this article can be found, in the online version, at http://dx.doi.org/10.1016/j.biortech.2015.07. 072 .

\section{References}

Aden, A., Ruth, M., Ibsen, K., Jechura, J., Neeves, K., Sheehan, J., Wallace, B., 2002. Lignocellulosic Biomass to Ethanol Process Design and Economics Utilizing CoCurrent Dilute Acid Prehydrolysis and Enzymatic Hydrolysis for corn stover National Renewable Energy Laboratory, Golden, Colorado.

Centre for Advanced Studies on Applied Economics, 2014 . <http:// www.cepea.esalq.usp.br>. 
Chen, J.C., Chou, C.C., 1993. Cane Sugar Handbook: a Manual for Cane Sugar Manufacturers and their Chemists. John Wiley and Sons.

CEPCI, 2010. CEPCI Index. <http://www.chemengonline.com/pci-home>.

Dias Paes, L.A., Marin, F.R., 2011. Carbon storage in sugarcane fields of Brazilian South-Central region. Centro de tecnologia canavieira, Technical report, São Paulo.

Dias, M.O.S., Ensinas, A.V., Nebra, S.A., Maciel Filho, R., Rossell, C.E., Maciel, M.R.W., 2009. Production of bioethanol and other bio-based materials from sugarcane bagasse: integration to conventional bioethanol production process. Chem. Eng. Res. Des. 87, 1206-1216.

Dias, M.O.S., Junqueira, T.L., Cavalett, O., Cunha, M.P., Jesus, C.D., Rossell, C.E., Macie Filho, R., Bonomi, A., 2010. Integrated versus stand-alone second generation ethanol production from sugarcane bagasse and trash. Bioresour. Technol. 103, $152-161$.

Dias, M.O., da Cunha, M.P., Maciel Filho, R., Bonomi, A., Jesus, C.D., Rossell, C.E., 2011 Simulation of integrated first and second generation bioethanol production from sugarcane: comparison between different biomass pretreatment methods. J. Ind. Microbial. Biotechnol. 38, 955-966.

Dias, M.O.S., Junqueira, T.L., Cavalett, O., Cunha, M.P., Jesus, C.D., Mantelatto, P.E., Rossell, C.E., Maciel Filho, R., Bonomi, A., 2013. Cogeneration in integrated first and second generation ethanol from sugarcane. Chem. Eng. Res. Des. 91, 14111417.

FitzPatrick, M., Champagne, P., Cunningham, M.F., Whitney, R.A., 2010. A biorefinery processing perspective: treatment of lignocellulosic materials for the production of value-added products. Bioresour. Technol. 101 (23) 8915-8922.

Furlan, F.F., Filho, R.T., Pinto, F.H., Costa, C.B., Cruz, A.J., Giordano, R.L., Giordano, R.C., 2013. Bioelectricity versus bioethanol from sugarcane bagasse: is it worth being flexible? Biotechnol. Biofuels 6, 142.

Goedkoop, M., Oele, M., Leijting, J., Ponsioen, T., Meijer, E., 2013. Introduction to LCA with SimaPro. PRé Consultants, the Netherlands.

Gnansounou, E., Dauriat, A., Villegas, J., Panichelli, L., 2010. Life cycle assessment of biofuels: energy and greenhouse gas balances. Bioresour. Technol. 100, 49194930.

Gnansounou, E., Dauriat, A., 2010. Techno-economic analysis of lignocellulosic ethanol: a review. Bioresour. Technol. 101, 4980-4991.
Gnansounou, E., Dauriat, A., Wyman, C.E., 2005. Refining sweet sorghum to ethanol and sugar: economic trade-offs in the context of North China. Bioresour. Technol. 96, 985-1002.

Hugot, E., 1986. Handbook of Sugar Engineering. Elsevier, Amsterdam.

Humbird, D., Davis, R., Tao, L., Kinchin, C., Hsu, D., Aden, A., Schoen, P., Lukas, J., Olthof, B., Worley, M., Sexton, D., Dudgeon, D., 2011. Process Design and Economics for Biochemical Conversion of Lignocellulosic Biomass to Ethanol. National Renewable Energy Laboratory Technical Report NREL. TP-5100-47764.

IEA, 2010. Sustainable Production of Second-Generation Biofuel. France, Paris.

IPCC, 2006. 4: Agriculture, Forestry and Other Land Uses (AFOLU): 2006 IPCC/ Guidelines for National Greenhouse Gas Inventories. IPCC/IGES, Hayama, Japan.

ISO, 2006a. ISO Norm 14040:2006: Life Cycle Assessment: Principles and Framework.

ISO, 2006b. ISO Norm 14044:2006: Life Cycle Assessment: Requirements and Guidelines.

Jenkins, G.H., 2013. Introduction to Cane Sugar Technology. Elsevier.

Larsen, J., Haven, M.Ø., Thirup, L., 2012. Inbicon makes lignocellulosic ethanol a commercial reality. Biomass Bioenergy 46, 36-45.

Larsen, J., Østergaard Petersen, M., Thirup, L., Wen Li, H., Krogh Iversen, F., 2008. The IBUS process - lignocellulosic bioethanol close to a commercial reality. Chem. Eng. Technol. 31, 765-772.

Meyer, J., Rein, P., Turner, P., Mathias, K., 2013. Good Management Practices for the Cane Sugar Industry. Bartens.

Lopes Silva, D.A., Delai, I., Delgado Montes, M.L., Roberto Ometto, A., 2014. Life cycle assessment of the sugarcane bagasse electricity generation in Brazil. Renew. Sustain. Energy Rev. 32, 532-547.

Moncada, J., El-Halwagi, M.M., Cardona, C.A., 2013. Techno-economic analysis for a sugarcane biorefinery: Colombian case. Bioresour. Technol. 135, 533-543.

Moreira, J.R., Pacca, S.A., Parente, V., 2014. The future of oil and bioethanol in Brazil. Energy Policy 65, 7-15.

Olbrich, H., 2006. The Molasses. Biotechnologie-Kempe GmbH.

Schaidle, J.A., Moline, C.J., Savage, P.E., 2011. Biorefinery sustainability assessment. Environ. Prog. Sustain. Energy 30, 743-753.

USDA Economic Research Service, 2014. Sugar and Sweeteners Yearbook Tables. <http://www.ers.usda.gov/data-products/sugar-and-sweeteners-yearbooktables.aspx>. 